\title{
Gadd45b knockout mice exhibit selective deficits in hippocampus-dependent long-term memory
}

\author{
Prescott T. Leach, ${ }^{1}$ Shane G. Poplawski, ${ }^{2}$ Justin W. Kenney, ${ }^{3}$ Barbara Hoffman, ${ }^{4}$ \\ Dan A. Liebermann, ${ }^{4}$ Ted Abel, ${ }^{2}$ and Thomas J. Gould ${ }^{1,5}$ \\ ${ }^{1}$ Department of Psychology, Neuroscience Program, Temple University, Philadelphia, Pennsylvania 19122, USA; ${ }^{2}$ Department of \\ Pharmacology, Department of Biology, University of Pennsylvania, Philadelphia, Pennsylvania 19104, USA; ${ }^{3}$ School of Biological \\ Sciences, University of Southampton, Southampton S017 1BJ, United Kingdom; ${ }^{4}$ Temple University School of Medicine, Fels Institute \\ for Cancer Research and Molecular Biology, Philadelphia, Pennsylvania 19140, USA
}

\begin{abstract}
Growth arrest and DNA damage-inducible $\beta$ (Gadd45b) has been shown to be involved in DNA demethylation and may be important for cognitive processes. Gadd45b is abnormally expressed in subjects with autism and psychosis, two disorders associated with cognitive deficits. Furthermore, several high-throughput screens have identified Gadd45b as a candidate plasticity-related gene. However, a direct demonstration of a link between Gadd45b and memory has not been established. The current studies first determined whether expression of the Gadd 45 family of genes was affected by contextual fear conditioning. Gadd45b, and to a lesser extent Gadd45g, were up-regulated in the hippocampus following contextual fear conditioning, whereas Gadd45a was not. Next, Gadd45b knockout mice were tested for contextual and cued fear conditioning. Gadd45b knockout mice exhibited a significant deficit in long-term contextual fear conditioning; however, they displayed normal levels of short-term contextual fear conditioning. No differences between Gadd45b knockout and wild-type mice were observed in cued fear conditioning. Because cued fear conditioning is hippocampus independent, while contextual fear conditioning is hippocampus dependent, the current studies suggest that Gadd $45 b$ may be important for long-term hippocampus-dependent memory storage. Therefore, Gadd $45 b$ may be a novel therapeutic target for the cognitive deficits associated with many neurodevelopmental, neurological, and psychiatric disorders.
\end{abstract}

Activity-dependent neural plasticity refers to the changes that occur in neural networks in response to stimulation (BruelJungerman et al. 2007). Plasticity-related genes are important for long-term memory acquisition, maintenance, and expression (Bliss and Collingridge 1993; Bruel-Jungerman et al. 2007). Upon neural stimulation, several genes are immediately up-regulated; these immediate early genes (IEGs) include c-Fos and Zif268 (for review, see Sheng and Greenberg 1990). A subset of these IEGs encode proteins that contribute to synaptic plasticity by acting as transcription factors that regulate the expression of other plasticity-related genes (Perez-Cadahia et al. 2011). Transcriptional up-regulation and de novo protein synthesis are required for longterm memory storage (Bourtchuladze et al. 1994; Abel et al. 1997). An additional transcriptional regulatory mechanism is DNA methylation, which occurs primarily at the cytosine residue of cytosine-phosphate-guanine $(\mathrm{CpG})$ dinucleotides. This phenomenon can physically hinder transcription-factor binding ( $\mathrm{Yu}$ et al. 2011). Expression of the growth arrest and DNA-damage-inducible $\beta$ (Gadd45b) gene, also known as myeloid differentiation primary response gene $(M y D 118)$, increases after neural stimulation (Nedivi et al. 1993; Hevroni et al. 1998; Ploski et al. 2006; Lemberger et al. 2008; Ma et al. 2009b) and is up-regulated by fear conditioning (Keeley et al. 2006). Gadd45b is important for the process of active demethylation of the promoter regions of select genes (Ma et al. 2009a,b; Wu and Sun 2009). Because DNA methylation restricts access of transcription factors to promoter regions, promoter demethylation can make these regulatory regions more accessible to transcription-factor binding. Gadd $45 b$

\section{${ }^{5}$ Corresponding author}

E-mail tgould@temple.edu

Article is online at http://www.learnmem.org/cgi/doi/10.1101/lm.024984.111. may therefore be critical for the neuronal response to activity and may affect the transcription of IEGs and their downstream targets through a positive feedback loop initiated by promoter demethylation.

The Gadd $45 b$ gene encodes a small (18-kDa) protein originally observed to play an important role in myeloid cellular response to cytokine exposure (Abdollahi et al. 1991). The functions ascribed to Gadd45b include hematopoietic cell differentiation and growth arrest (Liebermann and Hoffman 1998). The first study to suggest that Gadd45b may be a gene related to synaptic plasticity was conducted by Nedivi et al. (1993), who found an increase in hippocampal Gadd45b gene expression and other plasticity-associated genes, such as c-Fos and Zif268, after kainic acid-induced seizures. They concluded that Gadd45b may be a plasticity-related gene since multiple studies have shown that seizures induce synaptic changes similar to those seen with learning and long-term potentiation (LTP), the putative cellular correlate of learning-related plasticity (for review, see Ben-Ari and Represa 1990). A subsequent study demonstrated that Gadd45b induction after kainate-induced seizures was through a cyclic-adenosine monophosphate response element-binding protein (CREB)dependent mechanism (Lemberger et al. 2008). CREB is a transcription factor critical for hippocampus-dependent long-term memory formation (Bourtchuladze et al. 1994). In addition, increased Gadd45b expression was observed after LTP induction (Hevroni et al. 1998) alongside other well-established plasticityrelated genes, including Bdnf, Arc, c-Fos, and Zif268. Other manipulations that induce Gadd45b expression are exposure to a novel environment and exercise (Ma et al. 2009b), as well as electroconvulsive treatment (Ploski et al. 2006; Ma et al. 2009b). The aforementioned behavioral manipulations all induce neural plasticity (Ben-Ari and Represa 1990; Moser et al. 1993; Stranahan et al. 
2007). Thus, behavioral manipulations shown to induce Gadd45b gene expression are associated with changes in neural plasticity, but no studies to date have evaluated the functional contributions Gadd $45 b$ may make to synaptic plasticity and memory.

Understanding the effects of Gadd $45 b$ on cognitive processes may aid comprehension of and treatment for disorders with cognitive symptoms. Gene expression analysis has revealed reduced Gadd45b expression in brains of subjects with autism (Garbett et al. 2008). Autism is a developmental disorder characterized by social interaction deficits, communication deficits, and stereotyped behaviors along with abnormal cortical development/organization (Bailey et al. 1998) and specific perturbations in cognitive processes (Baron-Cohen 2004; Akshoomoff 2005). A reduction in Gadd $45 b$ in autistic brains may have functional consequences on cell cycle regulation, leading to alterations in brain size, structure, and function. Tissue from autistic subjects also exhibits altered DNA methylation patterns (Nguyen et al. 2010), which may be a consequence of deficient levels of Gadd45b. Subjects with autism display cognitive disturbances (Baron-Cohen 2004; Akshoomoff 2005) and altered Gadd45b expression may contribute to the cognitive symptoms associated with this disorder. Epigenetic abnormalities have also been identified for disorders that present with psychotic symptoms (Pidsley and Mill 2011). Patients with psychosis express a wide variety of DNA methylation alterations (Mill et al. 2008). Furthermore, Gadd45b gene expression is upregulated in this patient population, with reduced binding at the $B d n f$ promoter (Gavin et al. 2011b). Subjects with psychosis/ schizophrenia display cognitive disturbances (Barch 2005), and differences in Gadd45b expression and/or function may contribute to some of these symptoms as well.

The present studies sought to determine the functional contribution of Gadd $45 b$ to learning and memory using Gadd $45 b$ mutant mice (Gupta et al. 2005). Experiment 1 (A and B) evaluated the induction of Gadd45 family genes (Gadd45a, Gadd45b, and Gadd45g) in C57BL/6J male mice after contextual fear conditioning, a behavioral paradigm known to induce multiple IEGs and synaptic plasticity-related genes such as c-Fos, Zif268, Bdnf, and Arc (Keeley et al. 2006; Lubin et al. 2008; Czerniawski et al. 2011). Experiment 1, A and B, examined changes in Gadd45 family gene expression after two different training protocols to test whether the results are robust across different training protocols. Experiments 2-4 tested Gadd45b knockout (KO) mice in contextual and cued fear conditioning to determine the effect of this mutation on hippocampus-dependent and independent learning paradigms.

\section{Results}

\section{Experiment 1: Hippocampal}

\section{Gadd45 family gene expression in} male $\mathrm{C} 57 \mathrm{BL} / 6$ ] mice after contextual fear conditioning

Preliminary high-throughput gene expression experiments performed from mouse hippocampi 30 min after contextual fear conditioning indicated that gene expression of Gadd45b in the hippocampus was regulated at an early time point during memory consolidation (data not shown). Therefore, in Experiment $1 \mathrm{~A}$, we investigated whether gene expression of Gadd45 $b$ and its family members, Gadd45a and Gadd45g, memory consolidation after a single were altered in the hippocampus during footshock presentation (1.5 mA) administered in a novel context (contextual fear conditioning). We found that Gadd45b and Gadd45g gene expression was increased in the hippocampus 30 min after contextual conditioning: $t_{(14)}=9.885, P<0.05$ and $t_{(14)}=5.117, P<0.05$, respectively, whereas Gadd45a gene expression remained unchanged: $t_{(14)}=0.3393, P>0.05$ (Fig. 1A). To test whether altering the training procedures produced different changes in Gadd45 family gene expression, we conducted a follow-up experiment (Experiment 1B, shown in Fig. 1B) using a different conditioning paradigm $(2 \times 0.57-\mathrm{mA}$ footshocks). Further, a context exposure-only control was included to determine whether context learning alone was enough to drive gene-expression changes (with or without shock presentation). Omnibus analysis of Gadd45 family gene-expression changes after these behavioral paradigms (homecage, context-only exposure, or fear conditioning) revealed a significant effect of treatment on Gadd $45 b$ gene expression: $F_{(2,15)}=20.000, P<0.05$. Tukey's posthoc comparisons revealed that both context-only exposure and fear conditioning significantly increased Gadd45b gene expression $(P<0.05)$. Neither context-only exposure nor fear conditioning significantly affected Gadd45a or Gadd45g gene expression: $F_{(2,15)}=0.09197, P>0.05$ and $F_{(2,15)}=3.115, P>0.05$, respectively. Our findings indicate that hippocampal Gadd45b is up-regulated during memory consolidation following contextual learning, and that Gadd45g can be up-regulated following contextual fear conditioning under certain training protocols.

\section{Experiments 2-4: Short-term and long-term contextual fear conditioning in Gadd $45 b$ mutant mice and Gadd45 gene family expression in Gadd45b mutant mice}

Based on our gene-expression analysis, we sought to determine whether Gadd45b is important for hippocampus-dependent memory by evaluating mice that lack the Gadd45b gene (Gupta et al. 2005) in contextual fear conditioning. Gadd45b KO mice exhibited significantly less freezing to context $24 \mathrm{~h}$ after conditioning in the long-term memory test compared with wild-type (WT) mice ( $34 \pm 3.3 \%, n=10$ and $49 \pm 5.7 \%, n=7$, respectively): $t_{(15)}=2.374, P<0.05$ (Fig. 2). Gadd45b KO mice did not differ in short-term memory compared with WT controls when tested $1 \mathrm{~h}$ after conditioning ( $20 \pm 5.1 \%, n=7$ and $26 \pm 4.8 \%, n=9$, respecare specific to tasks that require de novo protein synthesis. RTqPCR was used to confirm that Gadd45b expression was eliminated in these mice and that other family members were not compensating for this deletion (Fig. 4). tively): $t_{(14)}=0.7826, P>0.05$ (Fig. 3), suggesting that the deficits
A

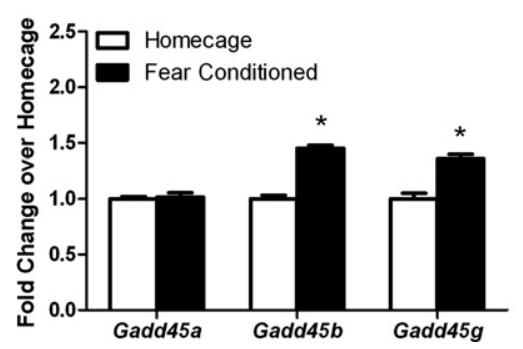

B

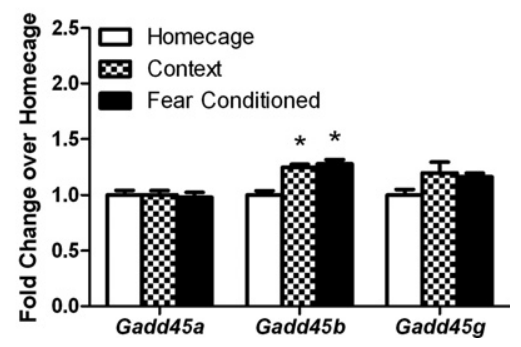

Figure 1. Comparison of hippocampal Gadd45 family gene expression after contextual fear conditioning in $\mathrm{C} 57 \mathrm{BL} / 6 \mathrm{~J}$ mice. (A) Gadd45b and Gadd45g mRNA were up-regulated in the hippocampus after contextual fear conditioning (1.5-mA footshock) compared with homecage (handled-only) controls. (B) Gadd45b mRNA was up-regulated in the hippocampus after contextual fear conditioning $(2 \times 0.57-\mathrm{mA}$ footshocks $)$ and context-only exposure compared with homecage (handled-only) controls. Error bars, \pm SEM. $\left({ }^{*}\right)$ Significantly different from the homecage (handled-only) group $(P<0.05)$. 


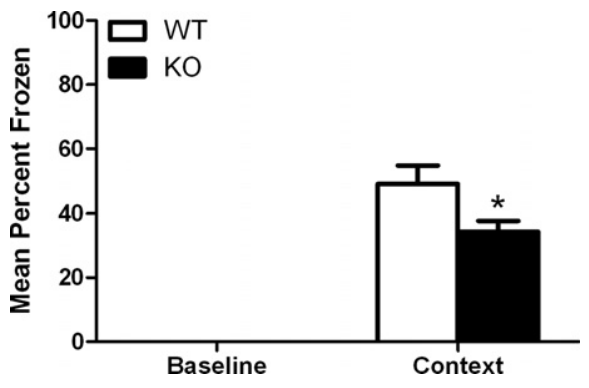

Figure 2. Comparison of long-term (24-h) contextual fear conditioning in Gadd $45 b$ WT and KO mice. Gadd $45 b$ KO mice froze significantly less to the context than WT mice. Error bars, \pm SEM. $\left(^{*}\right)$ Significantly different from WT $(P<0.05)$.

\section{Experiment 4: Long-term cued fear conditioning in Gadd45b mutant mice}

To determine whether long-term memory deficits were confined to hippocampus-dependent tasks, we evaluated Gadd45b mutant mice for cued fear conditioning, which depends on the amygdala but not the hippocampus (Logue et al. 1997). Gadd45b KO mice did not differ in cued conditioning compared with WT controls when tested $24 \mathrm{~h}$ after conditioning $(56 \pm 8.0 \%, n=7$ and $51 \pm$ $6.0 \%, n=9$, respectively): $t_{(14)}=0.588, P>0.05$ (Fig. 5), suggesting that the observed deficits in contextual conditioning are specific to hippocampus-dependent memory. Intact cued fear conditioning demonstrates sensory processing and motor function within the normal range and shows that fear memories can be learned and expressed normally.

\section{Discussion}

The present studies identify Gadd45b as an important gene for long-term hippocampus-dependent memory formation. Previous research showed Gadd45b induction in the hippocampus following various manipulations that induce synaptic changes (Nedivi et al. 1993; Hevroni et al. 1998; Ploski et al. 2006; Lemberger et al. 2008; Ma et al. 2009b). However, the role of this gene in synaptic plasticity as related to learning and memory processes was previously unknown. The current studies demonstrate a rapid and selective induction of Gadd45b gene expression in the hippocampus of C57BL/6J male mice 30 min after two distinct contextual fear-conditioning protocols and after context-only exposure, indicating a link between Gadd $45 b$ gene induction and exploration of a novel context. Furthermore, we determined that Gadd $45 b$ is functionally important for long-term hippocampusdependent memory by evaluating Gadd $45 b \mathrm{KO}$ mice in contextual fear conditioning $24 \mathrm{~h}$ after training. Gadd $45 b \mathrm{KO}$ mice exhibited a deficit in long-term hippocampus-dependent memory compared with WT mice, indicating that Gadd45b plays a key role in longterm memory. Gadd45b is selectively important for long-term hippocampus-dependent memory formation, which requires de novo protein synthesis (Abel et al. 1997; Bourtchouladze et al. 1998) and may be associated with active DNA demethylation (Lubin et al. 2008). Gadd45b KO mice showed no differences in short-term contextual fear conditioning $1 \mathrm{~h}$ after training compared with WT mice, a protein-synthesis-independent task (Abel et al. 1997; Bourtchouladze et al. 1998). Further, Gadd45b KO mice exhibited similar levels of delay-cued fear conditioning as WT mice, which has been demonstrated to be hippocampus independent (Phillips and LeDoux 1992; Logue et al. 1997). Normal delay-cued fear conditioning demonstrates that these mice are equally fearful after exposure to footshock, as assessed by their ability to exhibit the species typical fear response (freezing). This finding indicates that Gadd45b is not required for long-term hippocampus-independent memory, but instead is selectively important for long-term hippocampus-dependent memory.

The hippocampal gene-expression changes during memory consolidation that were observed in Experiment 1 prompted us to assess the importance of Gadd45b for successful memory consolidation. Since Gadd45b gene expression has also been reported in the amygdala (Keeley et al. 2006), characterization of Gadd45b mutant mice in both contextual and cued fear conditioning was warranted. We observed no functional consequences of Gadd $45 b$ deletion in cued fear conditioning, a task that relies on the amygdala but not the hippocampus (Phillips and LeDoux 1992). There is a well-established dissociation between contextual and cued conditioning, such as differential susceptibility to pharmacological disruption. For example, contextual fear conditioning is more sensitive than auditory cued fear conditioning to disruption by amnesic agents such as MK-801 (Gould et al. 2002; Goeldner et al. 2009) and scopolamine (Anagnostaras et al. 1999). Since hippocampus-dependent memories may be differentially more sensitive to disruption than hippocampus-independent memories, the selective impairment in contextual fear conditioning exhibited by Gadd $45 b \mathrm{KO}$ mice is in line with this dissociation.

The Gadd45 family of genes encode proteins that function as DNA repair molecules and may be critical for the process of de novo gene promoter demethylation, with Gadd45a being the best characterized in this regard (Barreto et al. 2007; Ma et al. 2009a). The putative mechanism whereby Gadd45 family gene products contribute to demethylation is by coupling deaminases and DNA base excision repair mechanisms (Rai et al. 2008). Despite its established role in DNA demethylation, however, Gadd45a showed no gene expression changes after any behavioral manipulation in the current studies. Further, Gadd $45 g$ gene expression was induced by some, but not all of the behavioral manipulations reported here. The current findings indicate that Gadd45a likely plays no role and that Gadd $45 \mathrm{~g}$ might play a role in contextual memory consolidation, but this effect would require further investigation.

Recent evidence demonstrated that contextual fear conditioning induces increased $B d n f$ gene expression and protein synthesis through Bdnf promoter demethylation (Lubin et al. 2008). Because of its role in activity-dependent synaptic plasticity (Bramham and Messaoudi 2005; Soule et al. 2006), BDNF signaling is regarded as a possible cellular correlate of hippocampus-dependent learning and memory (Linnarsson et al. 1997; Hall et al. 2000; Lu et al. 2008). Based on the work of Ma et al. (2009b), Gadd 45 b may be important specifically for the activity-dependent demethylation of the promoter region of the $B d n f$ gene, leading to

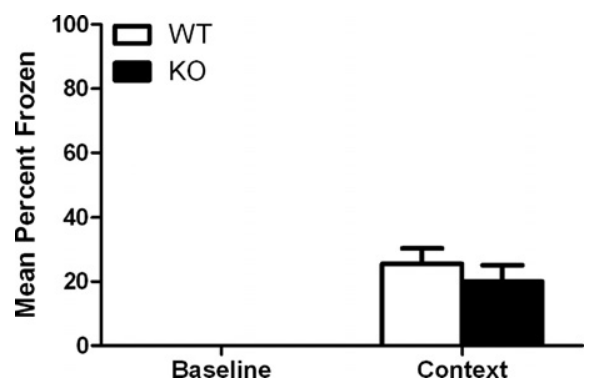

Figure 3. Comparison of short-term (1-h) contextual fear conditioning in Gadd $45 b$ WT and KO mice. Gadd45b KO mice froze to the same extent to the context as WT mice. Error bars, \pm SEM. 


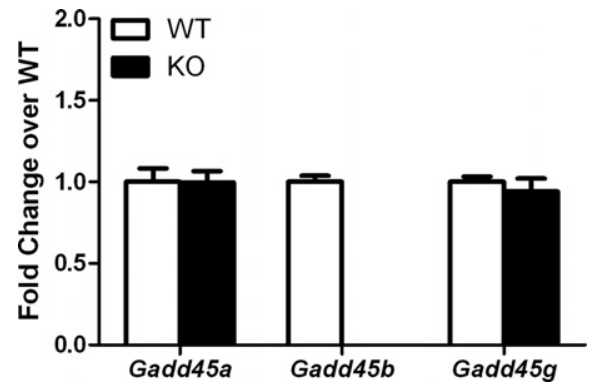

Figure 4. Comparison of hippocampal Gadd45 family gene expression after contextual fear conditioning in Gadd $45 b \mathrm{KO}$ and WT mice. Gadd $45 a$ and Gadd $45 \mathrm{~g}$ were unchanged in $\mathrm{KO}$ animals compared with WT controls, while Gadd45b expression was completely eliminated. Error bars, \pm SEM.

subsequent increases in gene and protein expression. Gadd $45 b$ may therefore directly contribute to the activity-dependent $B d n f$ promotor demethylation observed after contextual fear conditioning (Lubin et al. 2008), thereby increasing gene expression, protein synthesis, and plasticity-related signaling. The results of the current studies suggest that Gadd45b plays a crucial role in long-term hippocampus-dependent memory formation. One mechanism whereby Gadd45b may be important for memory is through its putative involvement in active DNA demethylation. Evidence for a direct role of Gadd45b in modulating Bdnf gene expression was recently demonstrated in Gadd $45 b \mathrm{KO}$ mice, which showed decreased $B d n f$ gene expression and increased $B d n f$ promoter methylation (Gavin et al. 2011a), implicating Gadd45b in the modulation of $B d n f$ gene expression through a DNA demethylation mediated pathway.

Abnormal expression of Gadd45b has recently been implicated in neurological and psychiatric disorders. Reduced cortical Gadd45b expression was reported in subjects with autism (Garbett et al. 2008), a neurological disorder characterized by cognitive symptoms (Baron-Cohen 2004; Akshoomoff 2005). Differences in DNA methylation patterns observed in autism (Nguyen et al.2010) may be a potential consequence of aberrations in Gadd45b expression. Individuals with psychosis also exhibit differences in global DNA methylation status (Mill et al. 2008) as well as increased Gadd $45 b$ gene and protein expression, with concomitant decreases in promoter binding (Gavin et al. 2011b). Therefore, Gadd $45 \mathrm{~b}$ may be a novel target for drug discovery research in the future. In fact, there is recent evidence that group II metabotropic glutamate receptor agonists and other antipsychotic agents may increase Gadd45b expression and protein levels (Matrisciano et al. 2011). Further, atypical antipsychotics show some efficacy in treating some of the symptoms of autism and may have beneficial effects on cognition (Barnard et al. 2002; Nikolov et al. 2006; Aman et al. 2008). Gadd45b is an intriguing gene that is important for active DNA demethylation, a mechanism potentially regulating the expression of other immediate early genes involved in synaptic plasticity and long-term memory. Additional studies will elucidate the extent to which activity-dependant DNA demethylation is involved in the cellular basis of learning and memory processes and show what role Gadd45b may play in these processes.

\section{Materials and Methods}

\section{Subjects}

For Experiment 1A, 8-wk-old male C57BL/6 mice (Jackson Laboratories, Bar Harbor, ME) arrived at the University of Pennsylvania and were allowed to acclimate for at least $1 \mathrm{wk}$ to a temperature and humidity-controlled vivarium with ad libitum access to standard rodent chow and water. Mice were single housed for $1 \mathrm{wk}$ and were gently handled for $3 \mathrm{~d}$ immediately prior to training. Mice were conditioned between 9 and $20 \mathrm{wk}$ of age. All procedures were approved by the University of Pennsylvania Institutional Animal Care and Use Committee. For Experiment $1 \mathrm{~B}$, animal housing and behavioral treatments were similar, but were conducted at Temple University, and all procedures were approved by the Temple University Institutional Animal Care and Use Committee.

For Experiments 2-5, Gadd45b KO and WT mice were originally obtained from the Temple Medical School (creation reported in Gupta et al. 2005). To ensure consistent background strain between WT and KO mice for behavioral comparison, Gadd45 $b$ KO mice were backcrossed to C57BL/6 mice (Jackson Laboratories, Bar Harbor, ME) in the Gould laboratory for five generations (N5) prior to filial heterozygous $\times$ heterozygous matings and conduct of subsequent fear-conditioning experiments (i.e., mice were generation N5F1-2). This backcrossing regimen is estimated to have produced mice $>95 \%$ genetically identical to C57BL/6 mice (Conner 2002). For Experiments 2-4, mice were bred and maintained at Temple University. Male and female mice were weaned at $21 \mathrm{~d}$ of age and tested at 8-12 wk. Mice were maintained in a temperature and humidity-controlled vivarium with ad libitum access to standard lab chow and water. Mice were single housed the week before testing, and gently handled for $3 \mathrm{~d}$ immediately preceding training. All procedures were approved by the Temple University Institutional Animal Care and Use Committee.

\section{Apparatus}

For Experiment 1A, fear conditioning was performed at the University of Pennsylvania. The conditioning chamber (MedAssociates) was $31.8 \times 25.4 \times 26.7 \mathrm{~cm}$, and all walls were made of Plexiglas. This training box was inside a larger Med-Associates opaque cubicle. The floor consisted of stainless-steel grid rods $3.2 \mathrm{~mm}$ in diameter, spaced $0.5 \mathrm{~cm}$ apart. A fan provided background noise at $70 \mathrm{~dB}$. Footshock was delivered by a MedAssociates solid-state shock source and grid floor scrambler that delivered a constant current $(1.5 \mathrm{~mA})$.

For Experiments $1 \mathrm{~B}$ and 2-4, fear-conditioning training and contextual fear-conditioning testing took place at Temple University in Plexiglas $(26.5 \times 20.4 \times 20.8 \mathrm{~cm})$ conditioning chambers containing stainless-steel rod grid floors (2-mm diameter) spaced $1.0 \mathrm{~cm}$ apart. Grid floors were connected to a scrambled shock generator (Med-Associates) that delivered $0.57-\mathrm{mA}$ footshocks. Conditioning chambers were controlled by a computer running LabView software. Conditioning chambers were housed inside sound-attenuating cubicles (Med-Associates) containing a house light (4 watt) and ventilation fan that produced a constant white noise $(65 \mathrm{~dB})$ and provided air circulation. Cued fear conditioning testing (Experiment 4) took place in separate chambers (an altered context $)$ of a different size $(20 \times 23 \times 19 \mathrm{~cm})$ contained within sound-attenuating cubicles (Med-Associates) located in a different room from conditioning chambers. The altered context chambers differed in construction such that they had Plexiglas

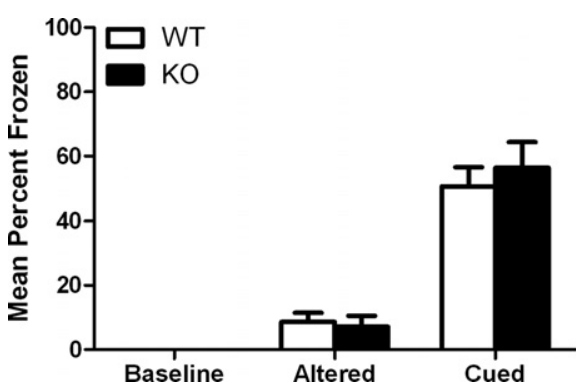

Figure 5. Comparison of long-term (24-h) cued fear conditioning in Gadd45b WT and KO mice. Gadd45b KO mice froze to the same extent to the cue as WT mice. Error bars, \pm SEM. 
front and back walls, aluminum side walls, and a flat plastic floor. Additionally, vanilla extract was added to alter the olfactory stimuli present in the chambers. All chambers were cleaned with $70 \%$ ethanol before and after each use.

\section{Experiment 1: Hippocampal Gadd45 family gene expression in male $\mathrm{C} 57 \mathrm{BL} / 6$ ] mice after contextual fear conditioning}

\section{RNA isolation after fear conditioning}

For Experiment 1A, fear conditioning was performed with a single 2 -sec footshock (1.5-mA) terminating 2 min and $30 \mathrm{sec}$ after introduction to the novel context. Thirty seconds after the shock, mice were removed from the novel context and placed back in their holding room. Hippocampi were dissected $30 \mathrm{~min}$ after training into RNAlater (Qiagen) and frozen on dry ice. RNA was extracted using the miRNeasy kit according to the manufacturer's protocol (Qiagen) and frozen at $-80^{\circ} \mathrm{C}$. This kit allows isolation of total RNA, including, but not limited to miRNA. Methods were designed and modeled after previous experiments (Vecsey et al. 2007). For Experiment 1B, fear conditioning was performed with two 2-sec footshock (0.57-mA) presentations, separated by a 148-sec intertrial interval. Thirty seconds after the last shock, mice were removed from the novel context and placed back in their holding room. Context-only exposure controls received identical time in the conditioning chamber in the absence of any footshock.

\section{CDNA synthesis and RT-PCR}

RNA concentration was determined using a NanoDrop spectrophotometer (Thermo Scientific), and $1 \mu \mathrm{g}$ of RNA was used in each RETROscript (Ambion) cDNA synthesis reaction with random decamers, $10 \times$ RT Buffer, and no heat denaturation, according to the manufacturer's protocol. cDNA reactions were diluted to $2 \mathrm{ng} / \mu \mathrm{L}$ in water, and real-time RT-PCR reactions were prepared in 384-well optical reaction plates with optical adhesive covers (ABI). Each reaction was composed of $5.4 \mu \mathrm{L}$ of cDNA $(2 \mathrm{ng} / \mu \mathrm{L}), 6 \mu \mathrm{L}$ of $2 \times$ Taqman Fast Universal Master Mix (ABI), and $0.6 \mu \mathrm{L}$ of one of the following Taqman probes: Gadd45a - Mm00432802_m1, Gadd45b - Mm00435123_m1, Gadd45g - Mm00442225_m1, Gapdh - Mm99999915_g1, Hprt - Mm01545399_m1, Tuba4a Mm00849767_s1 for Experiment 1A and 2.25 $\mu \mathrm{L}$ of cDNA, $2.5 \mu \mathrm{L}$ of master mix, and $0.25 \mu \mathrm{L}$ of probe for Experiment $1 \mathrm{~B}$. Reactions were performed in triplicate on the Viia7 Real-Time PCR system (Life Technologies). Relative quantification of gene expression between handled-only and fear-conditioned mice was performed using the $\Delta \Delta \mathrm{Ct}$ method as described previously (Vecsey et al. 2007). Briefly, the difference between each Ct and the average $\mathrm{Ct}$ for that gene was subtracted from the average of three housekeeper genes treated in the same manner.

\section{Experiments 2-4: Long-term and short-term contextual fear conditioning in Gadd45b mutant mice and evaluation of Gadd45 gene family levels in Gadd45b mutant mice}

Long-term contextual fear conditioning requires distinct neural processes from short-term contextual fear conditioning, such that long-term contextual fear conditioning requires de novo protein synthesis (Abel et al. 1997). Based on the hypothesis that Gadd45b is important for DNA demethylation leading to increased gene expression and de novo protein synthesis, we evaluated mice for short-term and long-term contextual fear conditioning. Mice were trained in contextual fear conditioning as previously described (Kenney et al. 2010). Mice were placed into conditioning chambers and allowed to explore for $2 \mathrm{~min}$ and $28 \mathrm{sec}$ before receiving the unconditioned stimulus (US, $0.57-\mathrm{mA}$ footshock) for $2 \mathrm{sec}$. Immediately following the shock, an intertrial interval of 2 min and 28 sec elapsed, after which a second US occurred. Mice were left in the chamber for $30 \mathrm{sec}$ after the last shock and then returned to their home cage. Mice were returned to the training context $24 \mathrm{~h}$ after training (Experiment 2; long-term) or $1 \mathrm{~h}$ after training (Experiment 3; short-term) and assessed for freezing to the context for $5 \mathrm{~min}$. Freezing to the context was used as a measure of contextual memory. For Gadd45 family gene expression (Experiment 4), $30 \mathrm{~min}$ after training mice were killed and RNA isolation, cDNA synthesis, and RTPCR were performed as described in Experiment 1A.

\section{Experiment 5: Long-term cued fear conditioning in Gadd45b mutant mice}

Mice were placed into conditioning chambers (as described above) and allowed to explore for $2 \mathrm{~min}$, at which time a conditioned stimulus (CS, white noise, $85 \mathrm{~dB}$ ) was presented continuously for $30 \mathrm{sec}$ and coterminated with the unconditioned stimulus (US, shock) lasting 2 sec. After the CS-US pairing, 2 min elapsed prior to a second CS-US pairing. Mice were returned to their home cages $30 \mathrm{sec}$ after the second CS-US pairing. Twenty-four hours after fear conditioning, mice were placed into an altered context and assessed for freezing for $3 \mathrm{~min}$. After $3 \mathrm{~min}$, the CS was presented continuously for an additional $3 \mathrm{~min}$. Freezing prior to the CS (altered context freezing) was used as a measure of generalized freezing, while freezing during the CS was used as a measure of fear memory (Gould and Lewis 2005).

For all behavioral experiments, mice were sampled for freezing once every $10 \mathrm{sec}$, and this measure was used as the dependent variable. Freezing was defined as lack of all movement other than respiration (Blanchard and Blanchard 1969). All testing was conducted by an experimenter blind as to the genotypes of the mice.

\section{Statistical analysis}

For qPCR experiments, all data were normalized to appropriate control genes (e.g., Gapdh, Hprt, and Tuba4a) and then expressed as a fold change over homecage (handled-only) control group (for Experiment 1, A and B) or as a fold change over WT (for Experiment 4). For Experiments $1 \mathrm{~A}$ and 4, independent samples $t$-tests compared hippocampal tissue from mice that remained in their homecage with fear-conditioned mice or between genotype. For Experiment 1B, one-way ANOVA compared gene expression after various treatments (homecage, context-only exposure, and fear conditioned). Significant omnibus tests were followed up by Tukey's pairwise comparisons to determine the nature of any significant effects. For fear-conditioning studies, independent samples $t$-tests were used to compare the percentage of time spent freezing between WT and KO mice, which was calculated as the number of times observed freezing divided by the total number of sampled time points expressed as a percentage of time spent freezing.

\section{Acknowledgments}

This work was funded with grant support from the National Institute on Drug Abuse (T.J.G., DA017949) and the National Institute of Mental Health (T.A., MH087463). P.T.L. and J.W.K. were supported by NIH-NIDA training grant DA07237 and S.G.P. was supported by training grant GM008076. We thank Josh Hawk for his assistance in tissue collections, and Kristy A. Cordero and Leonardo A. Ortega for their help with breeding, colony maintenance, and genotyping. We also thank Tatiana M. Kazdoba for reading and commenting on early drafts of this manuscript.

\section{References}

Abdollahi A, Lord KA, Hoffman-Liebermann B, Liebermann DA. 1991. Sequence and expression of a cDNA encoding MyD118: A novel myeloid differentiation primary response gene induced by multiple cytokines. Oncogene 6: 165-167.

Abel T, Nguyen PV, Barad M, Deuel TA, Kandel ER, Bourtchouladze R. 1997. Genetic demonstration of a role for PKA in the late phase of LTP and in hippocampus-based long-term memory. Cell 88: $615-626$.

Akshoomoff N. 2005. The neuropsychology of autistic spectrum disorders. Dev Neuropsychol 27: 307-310. 
Aman MG, Hollway JA, McDougle CJ, Scahill L, Tierney E, McCracken JT, Arnold LE, Vitiello B, Ritz L, Gavaletz A, et al. 2008. Cognitive effects of risperidone in children with autism and irritable behavior. J Child Adolesc Psychopharmacol 18: 227-236.

Anagnostaras SG, Maren S, Sage JR, Goodrich S, Fanselow MS. 1999. Scopolamine and Pavlovian fear conditioning in rats: Dose-effect analysis. Neuropsychopharmacology 21: 731-744.

Bailey A, Luthert P, Dean A, Harding B, Janota I, Montgomery M, Rutter M, Lantos P. 1998. A clinicopathological study of autism. Brain 121: $889-905$.

Barch DM. 2005. The cognitive neuroscience of schizophrenia. Annu Rev Clin Psychol 1: 321-353.

Barnard L, Young AH, Pearson J, Geddes J, O'Brien G. 2002. A systematic review of the use of atypical antipsychotics in autism. J Psychopharmacol 16: $93-101$.

Baron-Cohen S. 2004. The cognitive neuroscience of autism. J Neurol Neurosurg Psychiatry 75: 945-948.

Barreto G, Schafer A, Marhold J, Stach D, Swaminathan SK, Handa V, Doderlein G, Maltry N, Wu W, Lyko F, et al. 2007. Gadd45a promotes epigenetic gene activation by repair-mediated DNA demethylation. Nature 445: 671-675.

Ben-Ari Y, Represa A. 1990. Brief seizure episodes induce long-term potentiation and mossy fibre sprouting in the hippocampus. Trends Neurosci 13: 312-318.

Blanchard RJ, Blanchard DC. 1969. Crouching as an index of fear. J Comp Physiol Psychol 67: 370-375.

Bliss TV, Collingridge GL. 1993. A synaptic model of memory: Long-term potentiation in the hippocampus. Nature 361: 31-39.

Bourtchuladze R, Frenguelli B, Blendy J, Cioffi D, Schutz G, Silva AJ. 1994. Deficient long-term memory in mice with a targeted mutation of the cAMP-responsive element-binding protein. Cell 79: 59-68.

Bourtchouladze R, Abel T, Berman N, Gordon R, Lapidus K, Kandel ER. 1998. Different training procedures recruit either one or two critical periods for contextual memory consolidation, each of which requires protein synthesis and PKA. Learn Mem 5: 365-374.

Bramham CR, Messaoudi E. 2005. BDNF function in adult synaptic plasticity: The synaptic consolidation hypothesis. Prog Neurobiol 76: 99-125.

Bruel-Jungerman E, Davis S, Laroche S. 2007. Brain plasticity mechanisms and memory: A party of four. Neuroscientist 13: 492-505.

Conner DA. 2002. Mouse colony management. Curr Protoc Mol Biol doi: $10.1002 / 0471142727 . m b 2308 s 57$.

Czerniawski J, Ree F, Chia C, Ramamoorthi K, Kumata Y, Otto TA. 2011. The importance of having arc: Expression of the immediate-early gene arc is required for hippocampus-dependent fear conditioning and blocked by NMDA Receptor Antagonism. J Neurosci 31: 11200-11207.

Garbett K, Ebert PJ, Mitchell A, Lintas C, Manzi B, Mirnics K, Persico AM. 2008. Immune transcriptome alterations in the temporal cortex of subjects with autism. Neurobiol Dis 30: 303-311.

Gavin DP, Grayson DR, Guidotti A, Sharma RP. 2011a. Growth arrest and DNA-damage-inducible, $\beta$ (GADD45b) in psychosis. Program No 68120 Neuroscience Meeting Planner, Society for Neuroscience, Washington, DC.

Gavin DP, Sharma RP, Chase KA, Matrisciano F, Dong E, Guidotti A. 2011b. Growth Arrest and DNA-damage-inducible, $\beta$ (GADD45b)-mediated dna demethylation in major psychosis. Neuropsychopharmacology $\mathbf{3 7}$ 531-542.

Goeldner C, Reiss D, Wichmann J, Kieffer BL, Ouagazzal AM. 2009. Activation of nociceptin opioid peptide (NOP) receptor impairs contextual fear learning in mice through glutamatergic mechanisms. Neurobiol Learn Mem 91: 393-401.

Gould TJ, Lewis MC. 2005. Coantagonism of glutamate receptors and nicotinic acetylcholinergic receptors disrupts fear conditioning and latent inhibition of fear conditioning. Learn Mem 12: 389-398.

Gould TJ, McCarthy MM, Keith RA. 2002. MK-801 disrupts acquisition of contextual fear conditioning but enhances memory consolidation of cued fear conditioning. Behav Pharmacol 13: 287-294.

Gupta M, Gupta SK, Balliet AG, Hollander MC, Fornace AJ, Hoffman B, Liebermann DA. 2005. Hematopoietic cells from Gadd45a- and Gadd45b-deficient mice are sensitized to genotoxic-stress-induced apoptosis. Oncogene 24: 7170-7179.

Hall J, Thomas KL, Everitt BJ. 2000. Rapid and selective induction of BDNF expression in the hippocampus during contextual learning. Nat Neurosci 3: 533-535.

Hevroni D, Rattner A, Bundman M, Lederfein D, Gabarah A, Mangelus M, Silverman MA, Kedar H, Naor C, Kornuc M, et al. 1998. Hippocampal plasticity involves extensive gene induction and multiple cellular mechanisms. J Mol Neurosci 10: 75-98.

Keeley MB, Wood MA, Isiegas C, Stein J, Hellman K, Hannenhalli S, Abel T. 2006. Differential transcriptional response to nonassociative and associative components of classical fear conditioning in the amygdala and hippocampus. Learn Mem 13: 135-142.
Kenney JW, Florian C, Portugal GS, Abel T, Gould TJ. 2010. Involvement of hippocampal jun-N terminal kinase pathway in the enhancement of learning and memory by nicotine. Neuropsychopharmacology 35: 483-492.

Lemberger T, Parkitna JR, Chai M, Schutz G, Engblom D. 2008. CREB has a context-dependent role in activity-regulated transcription and maintains neuronal cholesterol homeostasis. FASEB J 22: 2872-2879.

Liebermann DA, Hoffman B. 1998. MyD genes in negative growth control. Oncogene 17: 3319-3329.

Linnarsson S, Bjorklund A, Ernfors P. 1997. Learning deficit in BDNF mutant mice. Eur J Neurosci 9: 2581-2587.

Logue SF, Paylor R, Wehner JM. 1997. Hippocampal lesions cause learning deficits in inbred mice in the Morris water maze and conditioned-fear task. Behav Neurosci 111: 104-113.

Lu Y, Christian K, Lu B. 2008. BDNF: A key regulator for protein synthesis-dependent LTP and long-term memory? Neurobiol Learn Mem 89: $312-323$.

Lubin FD, Roth TL, Sweatt JD. 2008. Epigenetic regulation of BDNF gene transcription in the consolidation of fear memory. J Neurosci 28: 10576-10586.

Ma DK, Guo JU, Ming GL, Song H. 2009a. DNA excision repair proteins and Gadd45 as molecular players for active DNA demethylation. Cell Cycle 8: $1526-1531$.

Ma DK, Jang MH, Guo JU, Kitabatake Y, Chang ML, Pow-Anpongkul N, Flavell RA, Lu B, Ming GL, Song H. 2009b. Neuronal activity-induced Gadd45b promotes epigenetic DNA demethylation and adult neurogenesis. Science 323: 1074-1077.

Matrisciano F, Dong E, Gavin DP, Nicoletti F, Guidotti A. 2011. Activation of group II metabotropic glutamate receptors promotes DNA demethylation in the mouse brain. Mol Pharmacol 80: 174-182.

Mill J, Tang T, Kaminsky Z, Khare T, Yazdanpanah S, Bouchard L, Jia P, Assadzadeh A, Flanagan J, Schumacher A, et al. 2008. Epigenomic profiling reveals DNA-methylation changes associated with major psychosis. Am J Hum Genet 82: 696-711.

Moser E, Moser MB, Andersen P. 1993. Synaptic potentiation in the rat dentate gyrus during exploratory learning. Neuroreport 5: 317-320.

Nedivi E, Hevroni D, Naot D, Israeli D, Citri Y. 1993. Numerous candidate plasticity-related genes revealed by differential cDNA cloning. Nature 363: $718-722$.

Nguyen A, Rauch TA, Pfeifer GP, Hu VW. 2010. Global methylation profiling of lymphoblastoid cell lines reveals epigenetic contributions to autism spectrum disorders and a novel autism candidate gene, RORA, whose protein product is reduced in autistic brain. FASEB J 24: $3036-3051$.

Nikolov R, Jonker J, Scahill L. 2006. Autistic disorder: Current psychopharmacological treatments and areas of interest for future developments. Rev Bras Psiquiatr 28: S39-S46.

Perez-Cadahia B, Drobic B, Davie JR. 2011. Activation and function of immediate-early genes in the nervous system. Biochem Cell Biol 89: $61-73$.

Phillips RG, LeDoux JE. 1992. Differential contribution of amygdala and hippocampus to cued and contextual fear conditioning. Behav Neurosci 106: $274-285$.

Pidsley R, Mill J. 2011. Epigenetic studies of psychosis: Current findings, methodological approaches, and implications for postmortem research. Biol Psychiatry 69: 146-156.

Ploski JE, Newton SS, Duman RS. 2006. Electroconvulsive seizure-induced gene expression profile of the hippocampus dentate gyrus granule cell layer. J Neurochem 99: 1122-1132.

Rai K, Huggins IJ, James SR, Karpf AR, Jones DA, Cairns BR. 2008. DNA demethylation in zebrafish involves the coupling of a deaminase, a glycosylase, and gadd45. Cell 135: 1201-1212.

Sheng M, Greenberg ME. 1990. The regulation and function of c-fos and other immediate early genes in the nervous system. Neuron 4: 477-485.

Soule J, Messaoudi E, Bramham CR. 2006. Brain-derived neurotrophic factor and control of synaptic consolidation in the adult brain. Biochem Soc Trans 34: 600-604.

Stranahan AM, Khalil D, Gould E. 2007. Running induces widespread structural alterations in the hippocampus and entorhinal cortex. Hippocampus 17: 1017-1022.

Vecsey CG, Hawk JD, Lattal KM, Stein JM, Fabian SA, Attner MA, Cabrera SM, McDonough CB, Brindle PK, Abel T, et al. 2007. Histone deacetylase inhibitors enhance memory and synaptic plasticity via CREB: CBP-dependent transcriptional activation. J Neurosci 27: 6128-6140.

Wu H, Sun YE. 2009. Reversing DNA methylation: New insights from neuronal activity-induced Gadd45b in adult neurogenesis. Sci Signal 2: pe17. doi: 10.1126/scisignal.264pe17.

Yu NK, Baek SH, Kaang BK. 2011. DNA methylation-mediated control of learning and memory. Mol Brain 4: 5. doi: 10.1186/1756-6606-4-5.

Received November 29, 2011; accepted in revised form May 15, 2012. 


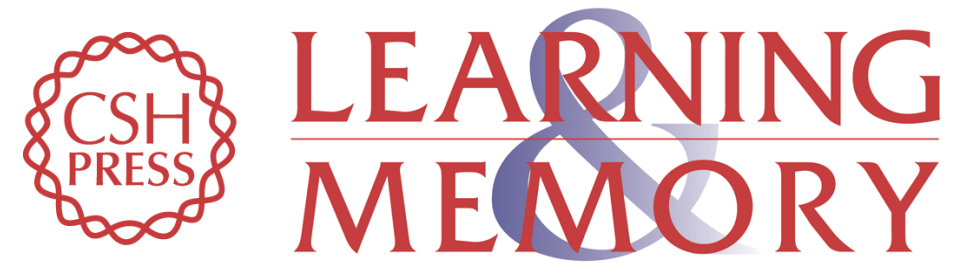

\section{Gadd45b knockout mice exhibit selective deficits in hippocampus-dependent long-term memory}

Prescott T. Leach, Shane G. Poplawski, Justin W. Kenney, et al.

Learn. Mem. 2012, 19:

Access the most recent version at doi:10.1101/lm.024984.111

References This article cites 54 articles, 10 of which can be accessed free at: http://learnmem.cshlp.org/content/19/8/319.full.html\#ref-list-1

License

Email Alerting Receive free email alerts when new articles cite this article - sign up in the box at the Service top right corner of the article or click here. 